\title{
Employability readiness for Aboriginal and Torres Strait Islander students: Yarning Circles as a methodological approach to illuminate student voice
}

\author{
Michelle J. Eady ${ }^{1}$ and Joel Keen ${ }^{1}$ \\ Corresponding author: Michelle J. Eady (meady@uow.edu.au) \\ ${ }^{1}$ University of Wollongong, Australia
}

\begin{abstract}
This paper describes the current situation for Aboriginal and Torres Strait Islander graduates entering the workforce and compares this with personal reflections from current Indigenous students engaged in the tertiary setting. The purpose is twofold: first, to promote Aboriginal and Torres Strait Islander student voice; and second, to provide an avenue for this voice to contribute to and influence the design of employability programs in higher education. This study examines how the use of Indigenous research methods, such as yarning/yarning circles, can effectively and ethically collect data to amplify and promote the student voice in ways that conventional Western research methods currently fail to do. This amplified voice can create a platform for researchers and practitioners to understand students' views and implement informed and tailored approaches to planning programs and delivering curriculum; in this case, employability-readiness skill sets for Aboriginal and Torres Strait Islander students in higher education. The findings are analysed thematically, and recommendations presented for higher-education institutions to consider when creating pedagogical approaches for the employability readiness of Aboriginal and Torres Strait Islander graduates.
\end{abstract}

Keywords: yarning circles, employability readiness, Aboriginal and Torres Strait Islander students, workintegrated learning, methodological approach

\section{Introduction}

Employability readiness in the tertiary sector has been a focal area for reform within higher education (Jackson, 2018; Small, Shacklock, \& Marchant, 2018). Indigenous Australian graduates have historically had a distinct trajectory and reduced rate of employment compared to their nonIndigenous counterparts (Behrendt, Larkin, Griew, \& Kelly, 2012; Social Research Centre, 2018). However, there are distinct characteristics and a common disconnect from Westernised conventions in the way that Indigenous Australian students are enabled to voice their perspectives on this issue. This study aims to understand Aboriginal and Torres Strait Islander student perspectives of employability readiness through a case study undertaken at the University of Wollongong (UOW), in partnership with the Woolyungah Indigenous Centre (WIC) and using the methodology that incorporates a traditional Indigenous method of sharing of ideas and information, called yarning circles (Bessarab \& Ng'andu, 2010; Fletcher et al., 2011; Lin et al., 2014; Mooney, Riley, \& Blacklock, 2018). This methodological approach provided an opportunity for the participating Aboriginal and Torres Strait Islander students to exercise their voice, and be heard and validated amongst their 
peers and the research team. The data collected and analysed for this study will also be used to inform the planning of future course content. In this case, the focus of interest was students' perceptions of their employability-readiness skill sets for Aboriginal and Torres Strait Islander students within higher education.

\section{Literature review}

\section{Historical comparisons of employability outcomes}

There is a recorded and ongoing comparison between Indigenous and non-Indigenous students' education and related employment outcomes. According to Behrendt, Larkin, Griew and Kelly (2012), the scale of differences between the two populations in these areas are disheartening. The Australian Government (2020) has reported that Indigenous university students have an attrition rate of $47 \%$, compared to $74 \%$ for non-Indigenous students, and a bachelor's degree completion rate of $45.5 \%$, compared to $72.6 \%$ for non-Indigenous students (Department of Education, 2014b), despite a clear increase in Indigenous Australian students' rate of participation in tertiary education. Over time, the issue of attrition has affected the rate of Indigenous employment in the workplace (Rigney, 2011). As 2018 statistics show, 49\% of Indigenous Australian graduates were employed full time, compared to $75 \%$ of non-Indigenous graduates (Australian Government, 2020, p. 65).

In comparison to the Australian population as a whole, Indigenous young people enrol in higher education or training less frequently, and are less likely to be fully employed or to engage in education at all (Australian Government, 2020). These ongoing statistics compound a preconceived impression that Indigenous students are at a higher risk of not completing their university studies (Australian Council for Educational Research, 2017; Wellington, 2019). Indigenous Australian students are not only seen as disadvantaged, but also increasingly marginalised, as they are rarely invited to participate in decision-making processes in institutions, which actively impedes the student voice (Gore, 2017; Mansouri, Jenkins, Morgan, \& Taouk, 2009; Wierenga \& Wyn, 2011).

\section{Work-integrated learning and student voice}

Work-integrated learning (WIL) pedagogy in tertiary-education settings is becoming more prevalent (Jackson, 2018; Martin et al., 2019). Many institutions have shifted their focus towards developing students' graduate employability skills (Clarke, 2017; Jackson, 2018; Oliver, 2015). WIL is defined at the University of Wollongong as activities that incorporate work practices within an academic institution/university setting; this can include activities on campus or in an actual workplace (Dean et al., 2018). More broadly, WIL aims to prepare students for employment by helping them gain graduate employability skills in their chosen field. WIL aims to catalyse opportunities for the entire student body; inclusivity is central to effective WIL practice. Inclusivity in WIL aims to:

1. Enable all students to have access to quality WIL;

2. Encourage awareness, respect and valuing of diversity;

3. Be practicable, workable and sustainable in different stakeholder contexts;

4. Take a holistic view of students' lives including their WIL experiences; and

5. Be proactive and collaborative (Winchester-Seeto et al., 2015, p. 2).

Globally, higher-education institutions have seen a shift towards fostering cultural competency within graduate outcomes (Foronda et al., 2018; Jackson, 2018). An example of this is the University of Sydney in Australia, which now includes 'cultural competence' in their graduate qualities (Harvey \& Russell-Mundine, 2019). The university adopted a system developed by the Centre for Australian, New Zealand and Pacific Studies (CANZPS) at Georgetown University, applying their definition: cultural competence is a set of congruent behaviours, attitudes and policies that come together in a system, agency or among professions' enabling that system, agency or those professionals to work 
effectively in cross-cultural situations (Cross, Bazron, Dennis, \& Isaacs, 1989, p. 28). The implementation of this strategy ensures the inclusion of relationships and collaborations with Aboriginal and Torres Strait Islander students, agencies and communities. For example, [o]ne of these relationships has been with an Indigenous Regional Assembly in NSW that developed an engagement model setting out principles guiding the ways in which the relationship between the Assembly and the University should be conducted (Harvey \& Russell-Mundine, 2019, p. 795). In turn, these collaborations have provided university students with WIL opportunities to both apply their critical-thinking skills and strengthen their disciplinary knowledge (Harvey \& Russell-Mundine, 2019). This presents a useful insight regarding the enhancement of Indigenous graduates' employability. Instead of viewing cultural competencies as a separate graduate quality or as integrated in separate subjects, it can become intrinsic to the process; variously interconnected between service-learning opportunities and the deconstruction of case studies with critical thinking, problem-solving and reflective practices (Lucas, 2017). These opportunities can assist students to extend their ways of knowing, being and doing (Martin, 2008).

The reflection process involved with WIL opportunities is not only valuable for the tertiary student but can also expand the knowledge of academics who develop WIL pedagogy. Participating in ongoing reflection can encourage academics to broaden their knowledge in the area of WIL and hear from their students directly (Martin, 2016, 2008). Student voice can help educators become aware of varied perspectives, values, opinions and beliefs that can be important factors in employability in a multicultural setting (St. John \& Briel, 2017). Research indicates that students who believe that they have a voice in their institution are seven times more likely to be motivated to undergo challenges than those who feel their voice is diminished (St. John \& Briel, 2017; Toshalis \& Nakkula, 2012). The issue of voice is particularly pertinent amongst Indigenous students in Australia, and it is essential that culturally appropriate data collection be particularly emphasised during any research that uses the student voice as empirical data (Denzin, Lincoln, \& Smith, 2008; Eady, 2010). Fredericks et al. (2017) state that cultural competency would ensure Indigenous involvement in university governance, management, teaching and learning, and research and a greater presence of Indigenous staff in the academy (p. 7). Therefore, normalising culturally competent methodologies inevitably shifts social research in a more ethical direction (Christians, 2000) and potentially allows for the Indigenous Australian student voice to provide a wealth of input for the benefit of tertiary academic contexts (Denzin, Lincoln, \& Smith, 2008).

According to Walsh, Black, Zyngier and Fernandes (2019), 'harnessing the student voice' has the power to transform the higher-education sector. It is well documented that the student voice can manifest in a number of ways. It has been proven to strengthen students' self-efficacy, and eventually encourage and give them the skills to make a difference in their education and communities (Lac \& Mansfield, 2018; Mitra, 2009, 2008, 2006; Mitra \& McCormick, 2017; Parker \& Neuharth-Pritchett, 2009). Indigenous and mainstream Australian ways of producing and enabling student voice often differ intrinsically (Donovan, 2015). To lessen the impact of these differences, a culturally appropriate data-collection method is imperative to quality research.

\section{Yarning - a way of embedding knowledge and perspectives}

A way of ethically enabling student voice within an Indigenous culture is through the method of yarning. Yarning is an Indigenous Australian method of in-depth group discussions to understand lived experiences and stories. It allows for a culturally safe method of engagement (Bessarab \& $\mathrm{Ng}$ 'andu, 2010, p. 37) and facilitates a deeply respectful autonomous space (Carlson \& Frazer, 2018) where everyone involved can embark on a journey together through discussion. Yarning is a way for Indigenous people to make sense of lived experiences, and to express who they are, where they are from and how they are connected (Geia, Hayes, \& Usher, 2013; Kovach, 2010; Martin et al., 2019). It can be used for many different purposes, such as informal discussions and formal meetings (Carlson \& Frazer, 2018), but more traditionally is used for sharing stories, histories, advice, laughter and tears (Imtoual, Kameniar, \& Bradley, 2009, p. 27). Yarning is useful for researchers to gain a deeper 
insight and understanding of how Indigenous culture can foster a place where mutual respect between Indigenous and non-Indigenous Australians can occur (Mooney, Riley, \& Blacklock, 2018).

Yarning as a research method can take various forms. Bessarab and $\mathrm{Ng}^{\prime}$ andu $(2010, \mathrm{p} .40)$ described four yarning methods:

1. Social Yarning: a relaxed, informal conversation where humour, advice and gossip are welcomed. The research topic is not introduced this early, and in this stage, trust must be built between the researcher and participants.

2. Research Topic Yarning: purposeful conversation in which the research topic is outlined. The researcher gains information related to their question through relaxed conversations.

3. Collaborative Yarning: conversation in which two or more participants talk about a topic related to the research question and/or discuss ideas about a research project.

4. Therapeutic Yarning: a conversation with the researcher where the participant discloses sensitive or personal information. This type of yarn gives voice to the participant; the researcher does not intervene, but actively listens.

Similarly, Lin et al. (2014) write that, according to data provided by Aboriginal participants, yarning as a research method provides an accurate and critical portrayal of the participants' inputs. It can help to alleviate any perception of the participants feeling questioned, as the topic is introduced in a deliberately open manner, and the yarning participants can then take that topic and respond as they see fit (Fletcher et al., 2011, p. 93).

Mooney, Riley and Blacklock (2018) studied research using yarning circles. The Indigenous participants spoke about their successes in the tertiary arena and the challenges that they faced. Consequently, unique insight was produced, allowing for new knowledge on Indigenous success to be generated. These types of results have immense future implications for both researchers and participants. When Indigenous voices are heard in a culturally appropriate and familiar method, the benefit extends well beyond the immediate research.

\section{Methodology}

Yarning circles were used as the primary method of qualitative data collection. Employability yarning circles approved through the UOW Human Research Ethics Committee (HREC 2019/255) took place on the $10^{\text {th }}$ and $17^{\text {th }}$ of September in 2018 at WIC, UOW. Potential participants were identified through their engagement with WIC and existing employability initiatives being conducted in collaboration with WIC. The main eligibility criterion was enrolled students' identification as Indigenous Australian, as recorded within the various UOW data-management systems. Eligibility was further refined by location, prioritising those students enrolled on the Wollongong campus. A total of 373 students fell into the eligible category. Study participants were recruited via a blanket email sent to Wollongong students self-identified as Indigenous Australian. Additionally, students who regularly engaged with WIC were encouraged in person by WIC staff members to participate, and verbally accepted or rejected the opportunity. All those students who accepted the offer to participate were included in the yarns. Participation was undertaken voluntarily by a total of 22 students across two yarning sessions: 10 students in yarn 1 and the remaining 12 in yarn 2 . Finalised sample groups consisted entirely of UOW Aboriginal and Torres Strait Islander students of various ages, ranging from 18-year-old high-school leavers transitioning to university study to non-schoolleaver students aged 50+. Given this range, participants' prior paid work experience and employment goals varied vastly, with each of the two yarn groups including participants looking to consolidate their past professional experience, those looking to commence pursuing a career upon completion of their studies and those engaged in up-skilling to facilitate a change in careers. Participants represented all stages of higher education offered at UOW, including college diploma, undergraduate and post-graduate degrees. First- and second-year undergraduate students provided the largest portion of sample group participants, with a total of 10 . The remaining participants 
contained a relatively even distribution of those in college courses, third- and fourth-year undergraduates, master's students and PhD students relatively evenly. Arts and Humanities degrees were most heavily represented, with six participants, followed by Commerce and Business and Education with three participants each; other disclosed areas of study were Law, Science, Politics, Philosophy and Public Health. To acknowledge the intersectional constitution of discrimination and align research findings with progressive notions undermining bias inherent in normative gender binary constructions, thus ensuring an inherent equality in service delivery, participants' gender was deliberately omitted from both the research design and subsequent analyses. Students were offered a $\$ 10$ university store voucher as a thank-you gesture for participation.

Yarning-circle discussion was facilitated by an external local Aboriginal organisation and conducted by an Indigenous Australian post-graduate UOW student employed by that organisation. Both yarning-circle sessions were conducted face-to-face and lasted approximately 160 minutes in total. Both were audio-recorded and transcribed. Beyond introducing the discussion topics, the facilitator assumed the role of a regular discussion participant, ensuring the negation of unbalanced power dynamics within the conversation. Within the yarning circle, students were asked to introduce themselves. Introductions included the participants' degree and current stage of study. After the casual introductory period, yarning was allowed to progress organically when possible. At the stalling of conversation, topics derived from the overarching employability research topic were introduced to produce qualitative data. Students were prompted to discuss their lived experiences, what available services they were aware of at UOW and WIC; which, if any, of those services they had used and contemplation on their future beyond university; and asked to identify ways that WIC could develop and foster employability skills for UOW Aboriginal and Torres Strait Islander students in preparation for graduation and employment. Yarning topics emphasised reflection on participants' experiences, imagination and expectations, thus producing unique insight into vital inclusions into future employability program designs.

A purpose of this study was to allow students the opportunity to influence the design of a sustainable informed employability model. This was particularly prioritised in the way that yarning was conducted. To emphasise this influence and adhere to a standard of ethics aligning with Indigenous research methodologies, the researchers and authors took special care to ensure that the student voice within discussion was not manipulated or re-contextualised, and that researchers' opinions were not imposed on the students' intended meanings. This method ensured studentcentredness, fostered and developed learning and supported cultural appropriateness in data collection and analyses.

Although the large variance in participants' age, area and stage of study, prior work experience and intended career was considered advantageous for this research project, the generality of the data extracted may also be considered a limitation. Future research intending to build on the findings of this study and contribute to the body of literature promoting yarning circles and Indigenous research methodologies may benefit from added specificity. Targeting specific demographics will allow further research to have a representative quality beyond that of the generalised Aboriginal and Torres Strait Islander students' category.

\section{Discussion}

The abundance, depth and richness of qualitative data gathered during these yarning circles clearly demonstrates the benefits of using yarning as a data-collection technique. The informal structure of yarning-circle discussion allows for the collection of qualitative data, not simply from direct discussion topics but also from associated issues perceived by participants. Throughout the exploration of employability issues, researchers were able to identify a range of perceived barriers to student success not anticipated in the research-design process. This richness and range of qualitative data not only helps to inform current student perspective, but also offers vital insight into future directions for associated research projects and program development and identifies gaps in the current knowledge base. Moreover, the benefits of yarning as a research method are not limited to 
the type of data produced. As with other critical Indigenous research methods and methodologies (Denzin, Lincoln, \& Smith, 2008), yarning is endowed with internalised notions of ethics that challenge normative Westernised notions of ethics (Christians, 2000) as an externally validated element of the research process (UOW, 2020). This increased emphasis on embodied ethics manifests in the context of transparency and genuine democracy inherent within the yarning process, including the allowance and amplification of students' voices.

By engaging in yarning as a data-collection method, a particular emphasis is placed on the validity of the Indigenous input and perspective. The lack of Indigenous input into the design and establishment of the social, political and economic institutions that constitute Australian society is well established academically (Gore, 2017; Mansouri, Jenkins, Morgan, \& Taouk, 2009). When Indigenous students, in an educational context, are given a voice it results in a sort of liberation (Freire, 2000), and creates an example of genuine democracy (Chomsky, 2003; Englund, 2000) alongside a promise of sustainable empowerment.

Although this study focuses on an Indigenous Australian sample group, it is important to contextualise increasingly ethical and sustainable research as beneficial to the entire population. The results produced, the amplification of 'ground-up' input - or laypersons' expertise - in the form of the student voice; institutional transparency and the subsequent notions of genuine democracy that it promotes, all potentially stand to benefit non-Indigenous students and staff members as well as the Indigenous student cohort. The insight provided through discussion and the collective Indigenous voice that was identifiable within thematic analysis presents a foundational plinth upon which reimagined, and more balanced, social structures can be built. In this case, the data was collected with the aim of improving the currently prolific WIL ambitions at UOW. As the results show, a wealth of information on how to improve the current approach, as the student perceives it, was obtained through the yarning-circle method. However, alongside this directly applicable data is a comprehensive body of less directly related data in neutral, positive and negative contexts that can potentially evoke a wide range of future research. If learning institutions are genuinely invested in producing comprehensively improved WIL and other employability-related programs that benefit all students equitably, it is important that they begin to prioritise the internalisation of ethics and sustainability that critical Indigenous research methodology, such as yarning circles, enables. Beyond the individualistic benefits experienced by students through the prioritisation of the student voice discussed earlier, making a concerted effort not only to give students a voice but to listen to and give purchase to that voice has the potential to affect the trustworthiness of institutional structures. Consequently, this effort stands to benefit not only the students allowed a voice but all those students of the future who engage in WIL employability initiatives.

\section{Results}

Students needed little encouragement to contribute to conversation. In this way, the yarning circles afforded a rich and meaningful discussion with the potential to contribute and influence employability program design. Concurrently, yarning's efficacy as a research tool was emphasised. Despite the wide range of experience covered by the sample group, attitudes towards employment and employability, particularly within tertiary education, proved to be surprisingly similar, and often resulted in consensus. The following section includes excerpts from yarning-circle discourse, contextualised with a brief descriptive discussion.

\section{Beyond university}

Understanding students' thoughts about how they imagine their careers after university produced thoughtful discussion, with yarns providing a mixed response of what students imagined for themselves relating to employment after graduation. This yarning topic was informative in establishing what a suitably ethical and sustainable employability model for Indigenous Australian graduates might entail. Some students expressed a clear vision of what they were going to do and 
where they wanted to be employed. Other students expressed that they were unsure of a clear career path to pursue and displayed uncertainty towards where their current paths might lead. This uncertainty also related to students considering a change in their degree or in fear of failing to complete their tertiary studies. The following excerpts accentuate the inconsistency of certainty expressed regarding employment after university. Participants' areas of study have been listed where possible; all degrees are bachelor's level unless otherwise specified.

I'm actually really unsure about my career in the future (Participant 1: Law).

I don't know what I'm doing...I want to be a successful writer (Participant 2: Undisclosed).

I kind of want to go into secondary teaching, teaching English and Indigenous studies...yeah so far, it could change (Participant 16: Arts).

I can't really picture afterwards because it really depends on what degree I get in afterwards, because I want Masters Clinical but I don't know if I'll get there (Participant 11: Psychology).

Fourteen of the 22 participants' responses were consistent with the quotes above. The scope of student discussion ranged from possessing a clear idea relating to their employment after graduation to complete confusion as to future employment prospects.

\section{External}

\section{Career Trackers internship support service}

A yarning topic was introduced to produce discussion on both external and internal employability supports that participants experienced while studying at UOW. The primary external support mechanism identified was Career Trackers (CT), a non-profit organisation that operates nation-wide, aiming to improve future employment outcomes by creating pathways and support systems for Indigenous young adults to attend and graduate from university (Career Trackers, 2020). CT aspires to maintain a student-centred focus to facilitate workplace experience as a complementary addition to the knowledge gained through obtaining a university degree. The interpretation of the data collected in this study revealed that almost universally, these participants were concerned about the direction that the service pushed them in and that it was not aligned with their interests, ambitions, area of study or career paths. The following excerpts highlight the feelings of the students who participated in the Career Tracker program:

[T]hey wanted me to go to different way of...like I don't want to...don't want to go to...I just don't like being pushed into somewhere I [don't] want to go.... So I had to walk out... (Participant 14: Arts).

Career Tracker people got an opportunity for me to work, I mean it's not really around what I want to do because they're sort of a real estate, I guess an opportunity for me to work on a project (Participant 7: Science Education).

They sat me down and talked to me, and they're like, 'Oh, yeah, you want to do that, but how about this?'(Participant 2: Undisclosed).

I'd like other opportunities too, you know (Participant 6: Arts)?

Yarning-circle consensus was that $\mathrm{CT}$ could successfully facilitate internships for students. However, the participants primarily expressed criticism for various aspects of the $\mathrm{CT}$ approach.

\section{Career consultants}

Discussion revealed similar themes of a lack of awareness and trust, particularly with respect to outsourcing the operation of internal support mechanisms. The following are direct excerpts from yarning transcripts: 
You know from experience...from our experience, it's all right saying yeah, we have some kind-hearted person down here say, 'We're going to talk to Indigenous students'. But at the end of the day, we're not a priority, unless we get somebody [Indigenous person] in there...to really push the issue, and they need to be a, quite blunt, it needs to be a Black fella, Black person, sorry (Participant 6: Arts).

The extended discussion surrounding the current careers consultants produced primarily critical feedback. Generally, students perceived these services as inherently futile. Additionally, most did not know that faculty career consultant services existed to help them find suitable internships and develop employability skills while studying.

\section{Internal}

\section{Computer skills}

Internally, students identified several services related to employability that they had experienced, or had had the opportunity to access, throughout their university study. Highlighting the necessity for holistic understanding in relation to optimising student support, these services are not explicitly designed to increase employability skills. The first internal service discussed as support that WIC received was in relation to developing computer skills. Participant 14, a Bachelor of Arts student, explained how he did not know how to type, nor use a computer, but was able to find support at the centre. This student went on to express a deep appreciation for the WIC staff who had taken the time to help him learn how to switch on a computer, use a printer, type etc. Participant 4 , studying Public Health, also supported this notion, noting that they [WIC] helped me in every way possible to try and get me through...even from getting on my computer.

These skills, fundamental for education, are also transferrable to employment in multiple applications. This was not a major discussion point; however, it proved fruitful in illuminating the holistic application of support needed to benefit employability across the entire student cohort. In addition to basic computer skills, student discussion focused primarily on internships offered internally at UOW.

\section{Internship subjects}

In discussing internships undertaken as an element of study, students exposed inequity within the current internal processes and related benefits. This inequity manifested in a range of cultural imbalances, from a general lack of cultural safety due to mainstream unconscious bias against Indigenous Australian cultures to overt racism that was fuelled by the ongoing reliance on the myth of the inherent superiority of Western ways of knowing. Expressing both positive outcomes from and negative feelings toward their internship experiences, the students consolidated the issues of relevance discussed above by highlighting a cultural imbalance underpinning the current approaches. Without the widespread adoption of a strength-based understanding of Indigenous Australian cultures, correcting this imbalance will continue to remain relatively unacknowledged and to impede Indigenous intern satisfaction. The lack of educational value was a particular sore point requiring further inquiry and discussion. Addressing this issue, one participant reflected on their experience:

[I]t devastated me because I learnt nothing, absolutely nothing, it didn't show me how an organisation operation works and...and I thought to myself, 'Well, I really want to go into the Aboriginal community anyway but at the end of the day I could've incorporated what I've learnt here.' ...l learnt nothing from it. Whereas...the non-Indigenous students that got to go to the Aboriginal organisation come back full of, like, 'We got taught this, we got taught that' (Participant 17: Arts).

Another participant advised that they had informed the relevant faculty of their negative experience but felt that not enough had been done to help correct the issue. Rather than presenting the student 
with a direct course of action, the faculty supplied advice that the student saw as a rationalisation of the implicit cultural bias that still exists within educational and occupational structures in Australia. Further discussion uncovered that the certification received for the internship came from the faculty and not from the employer, making the student feel that their efforts ticked an educational box but were undervalued by the employer.

During discussion, participants spoke of the importance of culturally safe spaces and being treated fairly in the workplace. This notion was supported by further yarning-circle consensus, where experiences of a lack of support in the workplace were expressed. These experiences led to a feeling that the internship process was designed to get Aboriginal people in where they're set up to fail without the appropriate support (Participant 5: Arts). Again, the participants heavily emphasised an almost invisible, yet ubiquitous, cultural imbalance within mainstream structures and practices.

\section{Co- and extra-curricular employment programs}

Further discussions of services offered at UOW showed that participants tended to be unaware of mainstream support mechanisms. The university has a prominent employability initiative that offers post-graduation recognition of co- and extra-curricular activities, including voluntary employment, in which students engage during their studies. This was addressed in only one instance. Participant 9, a PhD student, stated, I got offered, or asked to be a volunteer demonstrator for some of the subjects... and that goes on my, like, the [program] record. Yarning-circle dialogue emphasised a lack of awareness not just of the possible benefits of such programs but of the programs themselves.

Another yarning-circle participant shared that they had personally sought out and undertaken volunteer work at the local courthouse. The student was subsequently advised by fellow yarningcircle participants that, through the program, volunteer work and employability skills would appear on their academic transcript, and that this might assist in gaining future employment. Upon confirmation from the session facilitator that this advice was correct, the student replied, Yeah, but I don't want these people to know, like I don't... don't ask the system (Participant 14: Arts).

The yarning facilitator prompted discussion of the program in more detail to further gauge student familiarity with the university services. Common responses from students indicated that the majority had not been aware of this service. As a direct result, students did not enter into detailed discussion on this topic. The discussion then progressed to other student experiences at the university, revealing similarly low awareness. Participant sentiment was captured by the following statement:

Do we have...I'm pretty sure we have an Indigenous liaison or Indigenous recruitment office on board don't we? On campus? Is there? No? (Participant 6: Arts).

This statement reinforces the level of confusion that students experience in regard to the types of support available to them.

\section{Volunteering and networking workshop}

A generally more positive discussion relating to UOW employability initiatives was generated in relation to other university support mechanisms. One particular participant who spoke of their experience broached volunteering and networking workshops, feeling that the support they had received had facilitated the development of the necessary skills to engage with employers in a networking context:

I'm pretty lucky because with the [program], they teach us these skills. They found that like... because I'm a very shy person, I don't normally talk, I had people recommend me doing volunteering, so I started volunteering in [Faculty], and then someone recommended me to do the networking workshop that was just recently done. And that kind of helped me learn how to talk professionally to people, and if you want to get a job, this is how you should act and what you should say (Participant 18: UOW College Diploma). 
No other students spoke of being engaged in a networking workshop at the university. However, this topic universally sparked curiosity amongst the group members. The yarning participants all displayed surprise and were intrigued about this contribution.

\section{Findings}

\section{Employability: Supportive ways for consideration}

As a result of the shared interest, the discussion evolved to the creation of a list of suggestions from the yarning-circle participants. The participants brainstormed ideas, suggesting 'supportive ways' that WIC could assist Aboriginal and Torres Strait Islander students to be 'employability ready'. This list is presented below with an accompanying short outline of key topics.

\section{Long-term planning}

The majority of the yarning sessions focused on WIC providing long-term planning approaches towards enhancing employability skills. The students suggested that planning approaches should extend for the entire duration of a degree. The following are excerpts from the yarns, providing evidence of a student preference for increased long-term planning support:

I don't think there's a lot of conversation around how to be competitive, within our degrees. So we don't find this stuff out until the end.... Should we be doing volunteer stuff during our degree...demonstrating subjects... because I know [my degree] is a super highly competitive industry... So, I don't know whose responsibility that would be in the university but to talk to us about things we should be doing throughout our entire degree...to give us the edge when we graduate, when it comes to apply for jobs... rather than trying to get everything in that last year when you're [sic] already, you know, got a lot on (Participant 13: Nutrition Science).

Another topic considered was to ensure that faculties prescribe mandatory 'internship' subjects in different years of tertiary study; or that certain elements of employability-geared subjects be made compulsory.

Like just a day where maybe the faculty organises something within those subjects for all those students to attend, maybe it'll be all first-years, and then have another one for all second-years, whatever it may be, but just teaching those [employability] skills (Participant 12: Commerce).

\section{Check-in each year}

In the discussion, students suggested an individualised 'check-in' each year that would be geared to keep students on track with the employability-related elements of their learning experience. Students expressed concerns relating to time-management barriers and the perceived rush to gain employment towards the completion of their degree. These were shared concerns, and time was identified as a major barrier to managing an internship subject. In addition, students expressed that they did not feel that they had been scaffolded with the necessary skills to succeed in the workforce. It was suggested that career pathways be mapped out in the first year of tertiary study and repeat engagement undertaken for the duration of a degree. These excerpts from the yarning participants expressed the desire for a more constant supply of employability-related support:

....to talk about where you're at, if you're still on the right path (Participant 13: Nutrition Science).

...we all need to help each other to get through...and network it for everybody to help make us all employable in the end (Participant 12: Commerce). 


\section{Networking events and industry panels}

Students were intrigued by the idea of a networking event and a WIC-hosted industry panel. There was abundant discussion surrounding this topic, and numerous ideas to benefit students were proposed. Many students added their support to the idea of an employer networking opportunity. In particular, discussion emphasised WIC's ability to improve its networks with potential employers from both mainstream and Indigenous community organisations:

I think it would be cool if WIC could maybe help arrange industry panels...having people from specific industry that we can do a Q\&A with them or similar to a networking (Participant 18: UOW College Diploma).

\section{Developing employability skills}

In-depth conversation during the yarning was generated around the perceived need to build employability skills throughout tertiary study. Participants felt they needed more highly developed skills, but were unsure how to obtain them. Yarning participants raised and discussed ideas amongst themselves, theorising on how WIC could possibly provide additional opportunities to build employability skills:

...WIC to have availability of funds to sponsor students to attend like writing retreats or, you know, professional development type conferences within your specific faculty area (Participant 5: Arts);

...if we had a person that's going to sit down with us as students to talk about our degrees and where we want to go to before placing us into an internship or whatever it might be, actually talking to us about what we want to do and making sure that we're the right fit for that particular organisation or that particular placement (Participant 5: Arts).

\section{Wellbeing hub}

The idea of students creating a 'WIC Wellbeing Hub' became a talking point during discussion. Students expressed that a wellbeing hub could be universally beneficial amongst the Indigenous student cohort. It was suggested that students from all areas of study could maintain the wellbeing hub, using knowledge gained from their degree to learn, practice and develop employability skills. This was not a finely detailed discussion; however, students were excited about the idea and contributed enthusiastically:

Maybe Indigenous students stepping up and creating a wellbeing hub (Participant 22: Philosophy).

Our own little wellbeing centre here (Participant 21: Undisclosed).

\section{Indigenous employment specialist}

After unpacking the idea of a WIC wellbeing hub, discussion turned towards the topic of a WIC 'employment consultant' and making outreach the norm. This discussion coincided with many yarning-circle participants learning about the career consultant service through discussion, and that the career consultant was not an Indigenous person.

Participants' comments express their relevant perceived needs related to employability opportunities:

Why can't we have a specific identified position on campus, that does all that stuff (Participant 6: Arts)?

Working with students, not on students (Participant 5: Arts). 


\section{Recommendations}

Without deliberately being made a direct point of discussion, improved cultural safety was clearly the most prominent theme identified within the yarning circles. Often a sub-theme of what this paper has labelled as cultural imbalance, the issue of improved cultural safety as a facilitator to increased Indigenous engagement was framed within discussion as vital, even by those participants unable or unwilling to articulate that point in an explicit fashion. As a direct result, additional themes identified were deemed relevant to be included in the recommendations section of discussion due to their association to cultural safety. Recommendations address the additional themes of Indigenous support worker recruitment; building relationships and networking; relevant support; planning and mapping pathways; increasing awareness; and addressing uncertainty. Holistically, these recommendations address a large portion of the issue of cultural safety.

The following is a list of recommendations derived from yarning-circle discussions and subsequent data analysis. Recommendations are accompanied by brief discussion to provide additional context. It is intended that tertiary institutions adopt these recommendations for their own research and localised practice purposes. These recommendations are drawn from thematic analysis of discussion transcriptions, including those student suggestions arising from the discussions outlined above. In adhering to the structure of the yarning-circle discussion, points 2 through to 8 in the following list are underpinned by point 1 : cultural safety.

\section{Create culturally safe workplaces to better support Aboriginal and Torres Strait Islander graduates.}

Within organisations, the creation of culturally safe workplaces is a significant factor in any genuine attempt to support Indigenous Australian workers. In 2017, a longitudinal quantitative study that focused on labour-force transitions concluded that positive employment outcomes are more likely if organisations provide a culturally safe environment (Hunter \& Grey, 2017). This principle can be applied to students engaging in internships in the work environment. Aligned with the findings of Hunter and Grey (2017), Hutchins, Frances and Saggers (2009) produced a qualitative study concluding that improvements in Indigenous worker representation increase Indigenous employees' perceptions of safety in work environments. The proposed wellbeing hub and Indigenous employment specialist mentioned above emphasise students' concerns for their own wellbeing and the desire to 'work with' Indigenous employment staff, rather than have nonIndigenous 'experts' impart knowledge. Both of these themes strongly emphasise the need for students to feel culturally safe. Delivering cultural safety is not simply adjusting workplace practices and cultures to individual employees; it requires the 'embedding of the value and importance of cultural differences (Hutchins, Frances, \& Saggers, 2009, p. 7) within day-to-day workplace operations and protocols. The following recommendations align with this notion, providing practical examples of what some of these 'values and differences' are, and how relevant mainstream understandings of cultural safety can be progressed. Participants supported all these recommendations during the discussion, and explicitly aligned almost all of them with the overarching notion of improving cultural safety for Indigenous Australians.

\section{Recruit an Indigenous employment consultant to assist Aboriginal and Torres Strait Islander students obtain employability skills while studying.}

The results of the study clearly showed that the ability for non-Indigenous career consultants to associate with Indigenous Australian students' needs improvement. This improvement would be assisted greatly by including a reframed and collaborative, rather than paternalistic, dynamic between Indigenous and non-Indigenous Australians. Participants agreed amongst themselves that an Indigenous employment specialist or careers-related staff member was preferred. They commonly expressed that employability engagement would increase with an Indigenous person employed in the relevant position. This would directly improve notions of cultural safety and improve service relevance by prioritising an Indigenous perspective (St. John \& Briel, 2017). Arnold 
(2018) identifies that those administering support services assisting university students to transition into careers lack training in providing emotional support and offering advice for personal issues ( $p$. 8). This issue is compounded when dealing with Aboriginal and Torres Strait Islander students, given manifestation of complex traumas resulting from colonisation, alongside recognised inherent inequities within current national educational and employment frameworks. Student discussion strongly supported these notions.

\section{Build direct relationships between support centres and organisations to create employment opportunities.}

The participants expressed that establishing, maintaining and strengthening networks between potential employers and higher-learning support centres, such as WIC, serves to benefit them in various ways. Industry panels and other such initiatives, such as career expos, that attract an increasingly diverse array of employers necessarily appeal to a wider demographic amongst Indigenous Australian students. They also provide universities with an opportunity to use existing networking workshop structures to embed similar initiatives into university degrees, and to build on existing relationships to contribute to - and participate in - more external networking workshops. This addresses the suggestions raised during yarning-circle discussion that a networking workshop has the potential benefit of improving current employability models, and adds to the validity of the data collected.

Feeding information back to the employers in this scenario offers them increased exposure to and understanding of Indigenous Australian cultures and associated protocols. When used competently and respectfully, this improved understanding potentially manifests as normalised cultural safety within the workplace. Simmons (2019), Villalobos et al. (2016) and Downey et al. (2015) identify this normalisation as essential in reducing racialised, unconscious bias and improving institutional trustworthiness and employee engagement, as well as a range of improved additional outcomes for both employees and clients of culturally competent and inclusive workplaces. The prioritisation of cultural safety was emphasised throughout discussion, strongly supporting this notion of normalisation.

\section{Support students to engage in meaningful internships that are directly related to their area of study.}

Insights from the yarning circles indicate that internship facilitators are currently unable to provide meaningful support in securing internships equally suitable to both to the student and the industry partner. Binder, Baguley, Crook and Miller (2015) identify that students engaged in suitable internships experience a positive impact on future career development. A number of studies discuss this, and how it is seen to allow these students to apply and obtain for these jobs more easily, as well as increase the satisfaction of the internship and any potential future job (Binder, Baguley, Crook \& Miller, 2015; Conrad, 2020; Jackson, 2018). It is recognised that internships related to students' fields of study are the most attractive for job applicants (Schnoes et al., 2018). The yarning circle discussions supported these notions, identifying student engagement in suitably relevant, culturally safe internships as optimal for bolstering graduate employability. Suggestions of 'longterm planning' and regular 'check-ins' proposed in the discussions acknowledge the dynamism needed to ensure that ongoing engagement in employability initiatives remains relevant and meaningful. Additionally, processes should be implemented to ensure that concerns and complaints are addressed in ways that are meaningful to the student and prevent future students from experiencing the same concerns.

\section{Engage external Aboriginal employment services where appropriate.}

In regards to external services, participants discussed CT exclusively. This illuminates the importance of amplifying the Indigenous Australian student voice to inform and improve CT approaches to supporting Indigenous student employability. The yarning-circle discussions showed that improving CT's ethical and relevant engagement of Indigenous Australian tertiary students not only stands to

Eady, M J., \& Keen, J. (2021). Employability readiness for Aboriginal and Torres Strait Islander students: Yarning circles as a methodological approach to illuminate student voice. Journal of Teaching and Learning for Graduate Employability, 12(2), 1-18. 
benefit those Indigenous students already associated with CT initiatives, but also to improve CT's ability to engage Indigenous Australian students in the future. Students' suggestions illuminated that they understood the importance of developing employability skills while engaged in tertiary study, and indicated that a more holistic approach based in Indigenous methodologies of respectful, responsible and reciprocal story-sharing may improve employment services' efficacy in helping students become more employable (Kennedy et al., 2018).

\section{Implement a planning and mapping process for each Aboriginal and Torres Strait} Islander student from the commencement of a degree. Ensure that this planning process includes checking in regularly with the student (a minimum of once per semester) and that it identifies the employability skills each student needs to develop.

Calls within the discussions for a more individualised method of support for employability align with progressive notions of tertiary student support. Additionally, discussion participants explicitly called for this type of support to be provided in a long-term context. Behrendt, Larkin, Griew and Kelly (2012) identify personalised support in practice as content, delivered in culturally appropriate ways (p. 189). Put simply, increased individualisation in student support directly relates to an increase in culturally competent practice. This notion is strongly supported in the particularly pertinent context of online learning applications, where only an individualised approach ensures that students' needs [are] met in the most appropriate and effective ways (Stone, 2017, p. 6). The recommendation to introduce this personalised support in the context of employability also overtly reinforces the need for an Aboriginal employment support person, as previously recommended. As an integral element of the long-term and holistic support strategies best shaped to support Indigenous students, a role focused solely on employability allows for the yarning circles' ideas of 'mapping', 'checking in' and 'employability skills development' to be implemented in ways that embody cultural competence, acceptance and relevance.

\section{Increase awareness of co- and extra-curricular programs to allow for more opportunities for students to gain recognition for volunteer work.}

The yarning-circle discussions revealed a distinct lack of awareness of co- and extra-curricular activities available to students at UOW. In fact, even when individual awareness of these mechanisms was adequate, issues of institutional mistrust persisted as obstacles to Indigenous Australian students' willingness to engage with them. The confusion that the majority of yarningcircle participants expressed about how, when and why these programs exist and operate reinforces the need for increased student awareness levels of the practical benefits of mainstream UOW employability services, programs and supports. Without addressing this issue, we hypothesise that mainstream services will continue to struggle to achieve increased Indigenous engagement. However, without a concurrent effort to improve awareness of the rich diversity of Indigenous Australian cultures within these mechanisms, improvements in individual awareness of their existence will not necessarily translate to increased engagement (Lac \& Mansfield, 2018).

\section{Address issues of uncertainty about employability early in the tertiary education process.}

Addressing uncertainty about employability will be essential for any initiative intended to improve graduate employability. Improved articulation of the relevance of specific course content to future careers early in the employability skill-building process should be a prominent feature of any new graduate employability initiative. Additionally, existing initiatives should be improved to increase student certainty about the relevance of their degree to their intended professions. Currently, graduate employability initiatives and supports are falling short of addressing the issue of relevance in a way that adequately informs and promotes their participants' success.

It is testament to the yarning process as an intrinsically 'safe' research method that participants were comfortable about expressing the feeling that they were not treated fairly and equitably. The discussions also revealed that due to this summation, participants had overwhelmingly felt that they 
had missed a great opportunity to learn. In improving the efficacy of graduate employability initiatives, it is vital to understand the full complexity of the issues raised in the yarning circle. These issues should be the subject of further research carried out through critical Indigenous methodologies. The deconstruction of identified obstacles to success, and the problematisation of any initiatives, particularly one seen as an 'easy fix', are necessary in ensuring that current inequities are not allowed to continue.

\section{Conclusion}

Yarning circles conducted during the research project produced a wealth of data, much of which was unforeseen in research design. Subsequently, the documented potential of yarning circles as an effective, progressive data-extraction tool was not only achieved but was surpassed in many aspects. The semi-structured, yet intrinsically dynamic, constitution of yarning circles allowed participants to digress from the direct discussion of employability whilst exploring other relevant topics relating to the student experience. As a direct result, an exponentially more complex picture of those aspects of student life pertaining to employment and employability was achieved. Alongside the possible future benefits for students exposed to employability programs and initiatives informed by this data - the genuine student voice - a complementary immediate benefit is the opportunity for marginalised students to feel heard. Particularly within issues of employability relevant to higher education, the student perspective is considered paramount in achieving success. This identified current benefit establishes a foundation upon which the immediate benefits should be consolidated, as participants see recommendations derived from their input come to fruition within future employability programs and initiatives. These benefits, both immediate and potential, are positively influenced by the use of Indigenous research methodology, as input, analysis and outcomes are inherently contextualised within a culturally appropriate, ethical and strength-based framework that has historically been under-used within Australian approaches to research and structural reform.

To complement the empowerment achieved through Indigenous data-collection methods, this paper has been carefully authored with the highest priority being placed on amplifying the student voice without manipulating its intended meaning. In this context, genuinely enabling the Indigenous student voice advocates an essential increase in cultural safety on a societal level. Beyond the research process, using the student voice to develop new, progressive policy and change at all levels is needed to ensure the manifestation of culturally safe institutions (Connell, 2019; Donovan, 2015) as an inherent element of Australian society.

\section{References}

Arnold, W. W. (2018). Strengthening college support services to improve student transitioning to careers. Journal of College Teaching \& Learning), 15(1), 5-26.

Australian Government (2020). Closing the Gap report 2020. Department of the Prime Minister and Cabinet. https://www.niaa.gov.au/sites/default/files/reports/closing-the-gap-2019/sites/default/files/ctg-report20193872.pdf?a=1

Australian Council for Educational Research (ACER). (2017). Australian Education Review. https://research.acer.edu.au/cgi/viewcontent.cgi?article $=1027 \&$ context $=a e r$

Behrendt, L., Larkin, S., Griew, R., \& Kelly, P. (2012). Review of higher education access and outcomes for Aboriginal and Torres Strait Islander people: Final report. Department of Industry, Innovation, Science, Research and Tertiary Education.

Bessarab, D., \& Ng'andu, B. (2010). Yarning about yarning as a legitimate method in Indigenous research. International Journal of Critical Indigenous Studies, 3(1), 37-50.

Binder, J. F., Baguley, T., Crook, C., \& Miller, F. (2015). The academic value of internships: Benefits across disciplines and student backgrounds. Contemporary Educational Psychology, 41, 73-82.

Business Industry and Higher Education Collaboration Council (BIHECC) (2007). Graduate employability skills. Australia: DEST. Available at: https://core.ac.uk/download/pdf/30688676.pdf

Career Trackers (2020). About: Endless opportunities. Huge impact. https://www.careertrackers.org.au/about.

Eady, M J., \& Keen, J. (2021). Employability readiness for Aboriginal and Torres Strait Islander students: Yarning circles as a methodological approach to illuminate student voice. Journal of Teaching and Learning for Graduate Employability, 12(2), 1-18. 
Carlson, B., \& Frazer, R. (2018). Yarning circles and social media activism. Media International Australia, 169(1), 43-53.

Chomsky, N. (2003). Chomsky on democracy \& education. Psychology Press.

Christians, C. G. (2000). Ethics and politics in qualitative research. In N. K. Denzin \& Y. S. Lincoln (Eds.), Handbook of qualitative research (2nd ed) (pp. 133-155). Thousand Oaks: SAGE.

Clarke, M. (2017). Rethinking graduate employability: The role of capital, individual attributes and context. Studies in Higher Education, 43(11), 1923-1937. doi: 10.1080/03075079.2017.1294152

Connell, R. (2019). The good university: What universities actually do and why it's time for radical change. UK: Zed Books Ltd.

Conrad, S. S. (2020). Experiential learning: Preparing students for the workforce through faculty mentorship and feedback in campus-based IT projects. Journal of Computing Sciences in Colleges, 36(3), 142-150.

Cross, T. L., Bazron, B. J., Dennis, K. W., \& Isaacs, M. R. (1989). Towards a culturally competent system of care. US: Georgetown University Child Development Centre.

Dean, B., Eady. M., Glover-Chambers, T., Moroney, T., O’Donnell, N., \& Yanamandram, V. (2018). UOW WIL pedagogy: Definition, classifications and principles. NSW: University of Wollongong.

Denzin, N. K., Lincoln, Y. S., \& Smith, L.T. (2008). Handbook of critical and Indigenous methodologies. NY: SAGE Publications, Inc.

Department of Education (2014a). Selected higher education statistics: 2013 student summary. Canberra: Commonwealth of Australia. http://education.gov.au/selected-higher-education-statistics-time-seriesdata-and-publications

Department of Education (2014b). Completion rates of domestic bachelor students: A cohort analysis. Canberra: Commonwealth of Australia. http://education.gov.au/selected-higher-education-statisticstime-series-data-and-publications

Donovan, M. J. (2015). Aboriginal student stories, the missing voice to guide us towards change. Australian Educational Researcher, 42(5), 613-625. https://doi.org/10.1007/s13384-015-0182-3

Downey, S. N., van der Werff, L., Thomas, K. M., \& Plaut, V. C. (2015). The role of diversity practices and inclusion in promoting trust and employee engagement. Journal of Applied Social Psychology, 45(1), 3544.

Eady, M. (2010). Creating optimal literacy learning environments using synchronous technologies to support Aboriginal adult learners effectively: a Narungga perspective. Doctor of Philosophy thesis, Faculty of Education, University of Wollongong, 2010. http://ro.uow.edu.au/theses/3179

Englund, T. (2000). Rethinking democracy and education: Towards an education of deliberative citizens. Journal of Curriculum Studies, 32(2), 305-313.

Fletcher, G., Fredericks, B., Adams, K., Finlay, S., Andy, S., Briggs, L., \& Hall, R. (2011). Having a yarn about smoking: Using action research to develop a 'no smoking' policy within an Aboriginal health organisation. Health Policy, 103(1), 92-97.

Foronda, C. L., Baptiste, D. L., Pfaff, T., Velez, R., Reinholdt, M., Sanchez, M., \& Hudson, K. W. (2018). Cultural competency and cultural humility in simulation-based education: An integrative review. Clinical Simulation in Nursing, 15, 42-60.

Fredericks B., Kinnear S., Daniels C., Croft-Warcon P., \& Mann J. (2017) Perspectives on enabling education for Indigenous students at three comprehensive universities in regional Australia. In J. Frawley, S. Larkin\& J. Smith (Eds.), Indigenous pathways, transitions and participation in higher education (pp. 119-132). Springer. https://doi.org/10.1007/978-981-10-4062-7 8

Freire, P. (2000). Pedagogy of the oppressed. New York: Continuum.

Geia, L. K., Hayes, B., \& Usher, K. (2013). Yarning/Aboriginal storytelling: Towards an understanding of an Indigenous perspective and its implications for research practice. Contemporary Nurse, 46(1), $13-17$.

Gore, J. (2017). Why many high-achieving Indigenous students are shunning university. The Conversation. https://theconversation.com/why-many-high-achieving-indigenous-students-are-shunning-university79749

Harvey, A., \& Russell-Mundine, G. (2019). Decolonising the curriculum: Using graduate qualities to embed Indigenous knowledges at the academic cultural interface. Teaching in Higher Education, 24(6), 789-808.

Hunter, B., \& Gray, M. (2017). Dynamics of indigenous and non-indigenous labour markets. Australian Journal of Labour Economics, 20(1), 1-20.

Hutchins, T., Frances, K., \& Saggers, S. (2009). Improving the representation of Indigenous workers in the mainstream childcare workplace. Australasian Journal of Early Childhood, 34(1), 2-9.

Imtoual A., Kameniar, B., \& Bradley, D. (2009). Bottling the good stuff: Stories of hospitality and yarnin' in a multi-racial kindergarten. Australasian Journal of Early Childhood 34(2), 24-30. 
Jackson, D. (2018). Developing graduate career readiness in Australia: Shifting from extra-curricular internships to work-integrated learning. International Journal of Work-Integrated Learning, 19(1), 23-35.

Kennedy, J. E., Thomas, L. K., Percy, A. J., Delahunty, J., Harden-Thew, K., Martin, B., de Laat, M., \& Dean, B. A. (2018). Jindaola: An Aboriginal way of embedding knowledges and perspectives. Wollongong Australia: University of Wollongong.

Kovach, M. (2010). Conversational method in Indigenous research. First Peoples Child \& Family Review, 14(1), 123-136.

Lac, V. T., \& Mansfield, K. C. (2018). What do students have to do with educational leadership? Making a case for centering student voice. Journal of Research on Leadership Education, 13(1), 38-58.

Lin, I., Green, C., \& Bessarab, D. (2016). 'Yarn with me': Applying clinical yarning to improve clinician-patient communication in Aboriginal health care. Australian Journal of Primary Health, 22(5), 377-382.

Lin I., O'Sullivan, P., Coffin, J., Mak, D., Toussaint, S., \& Straker, L. (2014). I can sit and talk to her: Aboriginal people, chronic low back pain and healthcare practitioner communication. Australian Family Physician, 43(5), 320-324.

Lucas, P. (2017). Positioning critical reflection within cooperative education: A transactional model. Asia-Pacific Journal of Cooperative Education, 18(3), 257-268.

Mansouri, F., Jenkins, L., Morgan, L., \& Taouk, M. (2009). The impact of racism on the health and wellbeing of young Australians (2nd ed.). Melbourne: Foundation for Young Australians.

Martin, K. (2008). Please knock before you enter: Aboriginal regulation of outsiders and the implications for researchers. On line: Cambridge University Press.

Martin, K. L. (2016). Voices and visions: Aboriginal early childhood education in Australia. NSW: Pademelon Press.

Martin, R., Fernandes, C., Taylor, C., Crow, A., Headland, D., Shaw, N., \& Zammit, S. (2019). 'We don't want to live like this': The lived experience of dislocation, poor health, and homelessness for Western Australian Aboriginal People. Qualitative Health Research, 29(2), 159-172. https://doi.org/10.1177/1049732318797616

Martin, A. J., Rees, M., Fleming, J., Zegwaard, K. E., \& Vaughan, K. (2019). Work-integrated learning gone full circle: How prior placement experiences influenced workplace supervisors. International Journal of WorkIntegrated Learning, 20(3), 229-242.

Mitra, D. L. (2006). Youth as a bridge between home and school: Comparing student voice and parent involvement as strategies for change. Education and Urban Society, 38(4), 455-480. doi:10.1177/0013124506287911

Mitra, D. L. (2008). Strengthening student voice initiatives in high schools: An examination of the supports needed for school-based youth-adult partnerships. Youth \& Society, 40(3), 311-335. http://yas.sagepub.com/content/early/2008/04/01/00441 18X08316211.short

Mitra, D. L. (2009). Collaborating with students: Building youth-adult partnerships in schools. American Journal of Education, 115(3), 407-436. doi: 10.1086/597485

Mitra, D., \& McCormick, P. (2017). Ethical dilemmas of youth participatory action research in a democratic setting. International Journal of Inclusive Education, 21(3), 248-258.

Mooney, J., Riley, L., \& Blacklock, F. (2018). Yarning up: Stories of challenges and success. Australian Journal of Education, 62(3), 266-275.

Oliver, B. (2015). Redefining graduate employability and work-integrated learning: Proposals for effective higher education and disrupted economies. Journal of Teaching \& Learning \& Graduate Employability, 6(1), 56-65.

Parker, A. K., \& Neuharth-Pritchett, S. (2009). Calming rough waters: Teacher strategies for smoothing the transition to middle school. Childhood Education, 86(1), 20-26.

Rigney, L. (2011). Indigenous higher education reform and Indigenous knowledges. Canberra: Department of Education, Employment and Workplace Relations. http://docs.education.gov.au/documents/indigenoushigher-education-reform-and-indigenous-knowledges

Schnoes, A. M., Caliendo, A., Morand, J., Dillinger, T., Naffziger-Hirsch, M., Moses, B., ... O'Brien, T. C. (2018). Internship experiences contribute to confident career decision making for doctoral students in the life sciences. CBE Life Sciences Education, 17(1), ar16. doi:10.1187/cbe.17-08-0164

Simmons, D. N. (2019). You can't be emotionally intelligent without being culturally responsive: Why FCS must employ both to meet the needs of our nation. Journal of Family and Consumer Sciences, 111(2), 7-16.

Small, L., Shacklock, K., \& Marchant, T. (2018). Employability: A contemporary review for higher education stakeholders. Journal of Vocational Education \& Training, 70(1), 148-166.

Social Research Centre (SRC) (2018). 2018 Graduate Outcomes Survey-Longitudinal (GOS-L): Medium-term graduate outcomes. Canberra: Australian Government Department of Education and Training. 
Social Research Centre (SRC) (2018). 2018 Graduate Outcomes Survey. Canberra: Australian Government Department of Education and Training.

St. John, K., \& Briel, L. (2017). Student voice: A growing movement within education that benefits students and teachers. USA: VCU Center on Transition Innovations. https://vcurrtc.org/resources/viewcontent.cfm/1354

Stone, C. (2017). Opportunity through online learning: Improving student access, participation and success in higher education. National Centre for Student Equity in Higher Education (NCSEHE), Curtin University.

Toshalis, E., \& Nakkula, M. J. (2012). Motivation, engagement, and student voice. In N. Hoffman, A. Steinberg, \& R. Wolfe (Eds.), The students at the center series, 1-42. Washington, DC: Jobs for the Future.

University of Wollongong (UOW) (2020). Human ethics, research and innovation. www.uow.edu.au/researchand-innovation/researcher-support/ethics/human-ethics

Villalobos, B. T., Bridges, A. J., Anastasia, E. A., Ojeda, C. A., Hernández Rodriguez, J., \& Gomez, D. (2016). Effects of language concordance and interpreter use on therapeutic alliance in Spanish-speaking integrated behavioural health care patients. Psychological Services, 13(1), 49-59.

Walsh, L., Black, R., Zyngier, D., \& Fernandes, V., (2019). Harnessing student voice and leadership: A study of one Australian Indigenous leadership program. Pedagogy, Culture \& Society, 27(3), 383-401.

Wellington, S. (2019). Ambitious new targets for Indigenous students in NSW. NSW: NITV. https://www.sbs.com.au/nitv/article/2019/06/27/ambitious-new-targets-indigenous-students-nsw

Wierenga, A., \& Wyn, J., (2011). Generic Youth Development Framework: A discussion document for Department of Defence. Melbourne: Youth Research Centre, Melbourne Graduate School of Education, University of Melbourne.

Winchester-Seeto, T., Mackaway, J., Peach, D., Moore, K., Ferns, S., \& Campbell, M. (2015). Principles, guidelines and strategies for inclusive WIL: A resource for academics, practitioners and higher education institutions involved in the delivery of work integrated learning. In ACEN 2014: Conference Proceedings of the 2014 Australian Collaborative Education Network National Conference: Work Integrated Learning: Building Capacity. Victoria: ACEN. http://acen.edu.au/access-participation-progression/wpcontent/uploads/2015/11/FINAL-Principles-Guidelines and Strategies-Inclusive-WIL-as-at-6 11_15.pdf 